\title{
Study of Brain Radio Signals Using Bispectral Analysis
}

\author{
B.A. Hovhannisyan \\ Yerevan State University, 1 Alex Manoukian str., 0025, Yerevan, \\ Republic of Armenia \\ E-mail: babken.hovhannisyan.96@gmail.com
}

(Received: September 20, 2021; Revised: September 29, 2021; Accepted: October 9, 2021)

\begin{abstract}
Using a special sensor (probe antenna-applicator), radio signals emitted by the human brain are recorded. The changes of different parameters are investigated while studying different physical and emotional states of people. The studies are carried out using spectral and bispectral analysis in the LabVIEW environment. It is shown that in a stressful state the bispectrum of the brain's radio signal is significantly enriched, and many phase coupled spectral components appear. They undergo changes in their amplitude and frequency. The results of these studies may be useful for understanding the nature and identification of fast processes in the human brain.
\end{abstract}

Keywords: Electroencephalogram (EEG), bispectral analysis, spectral analysis, human brain signal, statistical signal processing

https://doi.org/10.52853/18291171-2021.14.3-138

\section{Introduction}

One of the main methods of studying the human brain and diagnosing various diseases associated with it is using the electroencephalograph (EEG) [1, 2]. The electroencephalograph records the voltage induced on the human scalp as a result of the ion currently in the brain's neurons.

EEG is a very subtle research method, and with its help it is possible to reveal the reaction of the brain to external stimuli affecting a person [3, 4], however, EEG is unable to reflect information connections among different parts of the brain and the activity of the higher nervous system: memory, thinking, intelligence, speech formation processes, etc. [3].

Many authors have also investigated the radio emission of biological objects, in particular the human brain [4-6], which, in addition to EEG signals, also emits electromagnetic radiation of the microwave range. However, these studies were carried out mainly with the help of radiometry and cannot reveal a correlation between the spectral components of radiation, as well as with fast processes in the brain.

In this work, radio signals emitted by the human brain were registered and the change in the parameters of these signals depending on the physical and emotional state of the person under study was investigated. The radio emission from the brain of 15 volunteers was studied, which was recorded using a special sensor (probe antenna-applicator).

Spectral analysis of the recorded signals shows that in the megahertz range the human brain emits radio radiation, which differs from the background. As a result of bispectral analysis of these signals, it was revealed that some groups of spectral components of this radiation exhibit internal correlation [7].

\section{Registration and analysis of human brain radio signals}

A block diagram of the equipment for recording and statistical processing of radio emission is shown in Fig. 1. It is identical to that described in [7]. 
The studies were carried out on 15 volunteer patients in the following way: a signal recorded using an antenna-applicator applied to the patient's head via a coaxial cable was served to a statistical processing system (see Fig. 1). In the processing system, after filtering the background component of the signal, its spectral and bispectral analysis was carried out in the LabVIEW environment. The results of the statistical processing were displayed on a computer monitor.

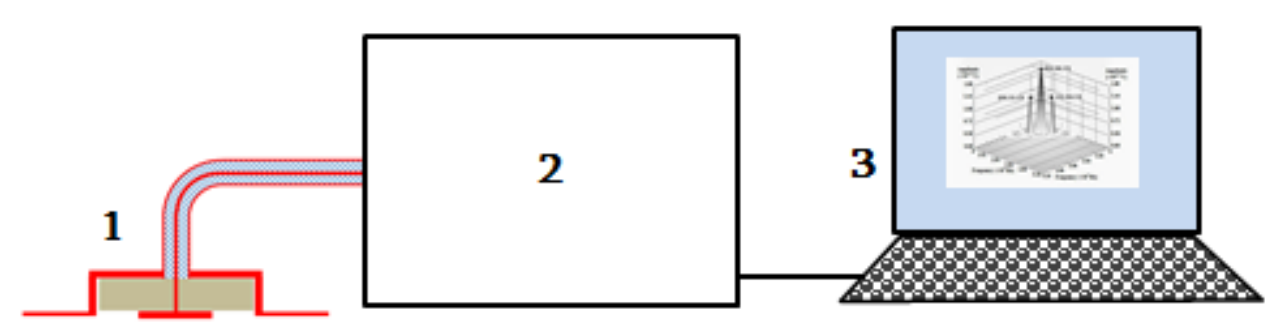

Fig. 1. Block diagram of the system for registration and analysis of brain radio signals: 1- probe antenna-applicator, 2 - NI-cRIO 9042, 3 - PC.

Spectral analysis was carried out in accordance with the formula for the discrete Fourier transformation [8]:

$$
S(n)=\frac{1}{N} \sum_{k=0}^{N-1} s\left(t_{k}\right) \exp \left(-\frac{j 2 \pi n k}{N}\right)
$$

where $\mathrm{s}(\mathrm{k})$ is the sample value of the signal taken at times $t_{k}=\frac{k T_{a}}{N}, T_{a}$ is the total duration of the signal (analysis time), $\mathrm{N}$ is the number of samples, and $j=\sqrt{-1}$.

In the absence of a constant component of the signal, the bispectrum can be expressed through the spectra of realizations of a random $\operatorname{signal} \dot{S}^{(i)}(m)$ [9]:

$$
\dot{B}_{S}(m, n)=\left\langle\dot{S}^{(i)}(m) \dot{S}^{(i)}(n) \dot{S}^{*(i)}(m+n)\right\rangle=\left\langle\dot{S}^{(i)}(m) \dot{S}^{(i)}(n) \dot{S}^{(i)}(-m-n)\right\rangle
$$

Bispectrum is the average statistical value of the triple product of the spectra at frequencies $\mathrm{m}$, $\mathrm{n}$ and the complex conjugate spectrum at the frequency $\mathrm{m}+\mathrm{n}$, which characterizes the mutual correlations among the spectral components of the process at these three frequencies. Bispectral analysis of the signal was performed according to formula (2).

To ensure statistical accuracy, the signal received from each patient was recorded for a sufficiently long time ( $\mathrm{T} \_\mathrm{a} \sim 10$ minutes) in a room isolated from external influences.

Spectral analysis of the recorded signal shows that there is radiation near $15 \mathrm{MHz}$, which differs from the background.

As noted above, the studies were conducted with various physical and emotional states of the studied volunteers.

The results of bispectral analysis of the signal received from a volunteer in a calm state are presented in Fig. 2.

The figure shows the spectral components of the signals ( $f \_1 \approx 8 \mathrm{MHz}$ and $\mathrm{f}_{-} 2 \approx 15 \mathrm{MHz}$ ), among which there are correlations. The bispectrum at these frequencies differs significantly from the background. The graph also shows other, relatively weaker (f_3 $\approx 8 \mathrm{MHz}$ and f_4 $\approx 18 \mathrm{MHz}$, etc.) spectral components that differ from the background. 


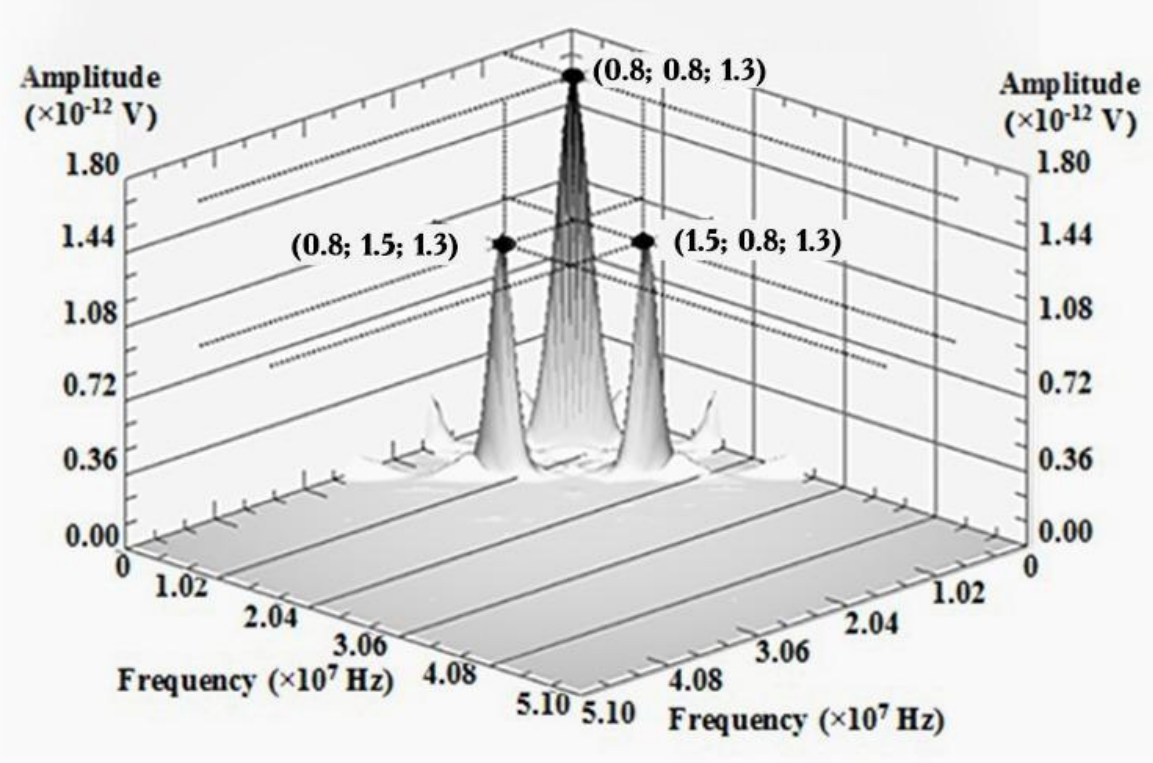

Fig. 2. Bispectrum of the human brain radio signal in calm state.

The nature of the signal's bispectrum varies greatly under the patient's stressful state. So, for example, if a volunteer corresponded to the bispectrum shown in Fig. 2 in a calm state, in a stressful state the bispectrum is greatly enriched, many spectral components correlated with each other appeared. The signal bispectrum of this volunteer under stress is shown in Fig. 3. It should be noted that the change in the human condition does not cause a noticeable change in the spectrum of the registered signal.

In addition to the appearance of new spectral components correlated with each other, the amplitudes of the spectral components also change ( $\sim 5$ times). The frequencies of the crosscorrelated components also partially changed.

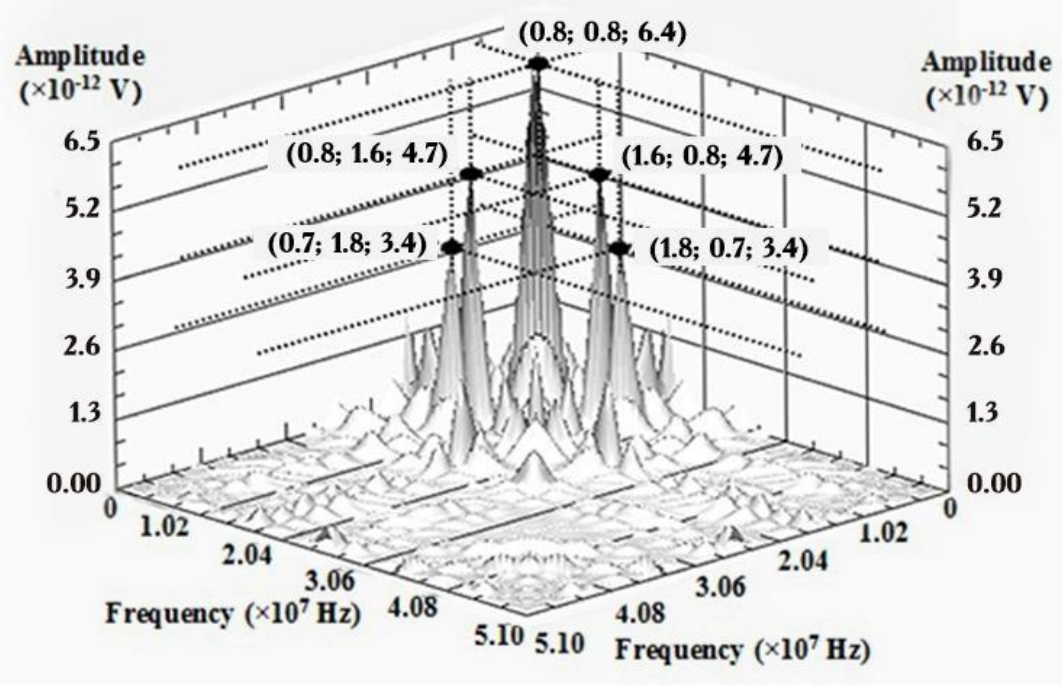

Fig. 3. Bispectrum of the human brain radio signal in stress state.

It should be noted that changes in the bispectrum of signals received from the tested volunteers, with a change in their physical and emotional state, had a similar character.

Thus, a comparative analysis of the spectra and bispectral of 15 volunteer patients in various physical and emotional states indicates that, in the spectral composition of the radio signal of the human brain, there are correlated components in the megahertz range, the frequencies of which 
differ slightly from each other in different people, but in a quiet state they mostly waver among the same values $(8 \mathrm{MHz}, 15 \mathrm{MHz}, 18 \mathrm{MHz}$, etc.). In a stressful state, the bispectrum is greatly enriched, new spectral components appear, correlated with each other.

\section{Conclusion}

Using the probe antenna applicator, radio signals were recorded in the megahertz frequency range. As it was shown the acquired signals have phase coupled components that are related to human physical and psychological states. In a stressful state, the bispectrum is greatly enriched, new spectral components appear that are correlated with each other, the amplitudes of the spectral components increase, and the frequencies of the cross-correlated components partially change. These study results can be useful for understanding nature and for identifying fast processes in the human brain, and, as a result, for the diagnosis and treatment of various human diseases associated with the brain.

\section{References}

[1] Maturana-Candelas, Frontiers in Computational Neuroscience 14 (2020) 70.

[2] C. Gómez, $39^{\text {th }}$ Annual Intern. Conf. of the IEEE Engineering in Medicine and Biology Society (2017) 422.

[3] P.A. Abhang, B.W. Gawali, S.C. Mehrotra, Introduction to EEG - and Speech-Based Emotion Recognition (Academic Press 2016) 19.

[4] Л.И. Брусиловский, А.С. Брюховецкий, С.П. Кожин, П.Г. Серафимович, А.В. Никоноров, Журнал радиоэлектроники 2 (2020).

[5] J.W. Hand, G.M.J. Van Leeuwen, S. Mizushina, Physics in Medicine and Biology 46 (2001) 1885.

[6] K. Maruyama, IEEE Transactions on Microwave Theory and Techniques 48 (2000) 2141.

[7] H.L. Ayvazyan, S.V. Antonyan, A.O. Makaryan, B.A. Hovhannisyan, E.R. Sivolenko, G.A. Tsaturyan, Journal of Contemporary Physics (Armenian Academy of Sciences) 56 (2021) 4.

[8] С.И. Баскаков, Радиотехнические цепи и сигналы (Москва, Высшая школа, 2000).

[9] А.А. Зеленский, В.Ф. Кравченко, В.В. Павликов, А.В. Тоцкий, Физические основы приборостроения 3 (2013) 4. 